\title{
Translation and measurement properties of the Swedish version of ACL-Return to Sports after Injury questionnaire
}

Joanna Kvist, Annika Österberg, Håkan Gauffin, Sofi Tagesson, K Webster and C Ardern

\section{Linköping University Post Print}

\section{Tweet}

N.B.: When citing this work, cite the original article.

This is the pre-reviewed version of the following article:

Joanna Kvist, Annika Österberg, Håkan Gauffin, Sofi Tagesson, K Webster and C Ardern, Translation and measurement properties of the Swedish version of ACL-Return to Sports after Injury questionnaire, 2013, Scandinavian Journal of Medicine and Science in Sports, (23), 5, 568-575.

which has been published in final form at:

http://dx.doi.org/10.1111/j.1600-0838.2011.01438.x

Copyright: Wiley-Blackwell

http://eu.wiley.com/WileyCDA/Brand/id-35.html

Postprint available at: Linköping University Electronic Press http://urn.kb.se/resolve?urn=urn:nbn:se:liu:diva-100312 
Translation and measurement properties of the Swedish version of ACL- Return to Sports after Injury questionnaire

J Kvist ${ }^{1}$, A Österberg ${ }^{1,2}$, H Gauffin ${ }^{3}$, S Tagesson ${ }^{1}$, K Webster $^{4}$, C Ardern ${ }^{4}$

${ }^{1}$ Division of Physiotherapy, Department of Medical and Health Sciences, Linköping University, SE-581 53 Linköping, Sweden

${ }^{2}$ Department of Physical Therapy, Kullbergska Hospital, Katrineholm, Sweden

${ }^{3}$ Division of Inflammation Medicine / Orthopaedics and Sports Medicine, Department of Clinical and Experimental Medicine, Linköping University, SE-581 53 Linköping, Sweden

${ }^{4}$ Musculoskeletal Research Centre, La Trobe University, Melbourne, Australia

Corresponding author:

Joanna Kvist, Division of Physiotherapy, Department of Medical and Health Sciences, Linköping University, SE-581 53 Linköping, Sweden

Phone: +46101031754

Fax: +46101031706

E-mail: joanna.kvist@liu.se

Running head: Measurement properties ACL-RSI 


\section{ABSTRACT}

Psychological factors may be a hindrance for returning to sport after an $A C L$ reconstruction. The ACL-Return to Sport after Injury scale (ACL-RSI) measures athletes' emotions, confidence in performance and risk appraisal in relation to return to sport. The aim of this study was to translate the ACL-RSI scale from English to Swedish and to examine some of the measurement properties of the Swedish version. The ACL-RSI was translated and culturally adapted. A professional expert group and five patients evaluated face validity. One hundred and eighty-two patients completed the translated ACL-RSI, a project specific questionnaire, the Tampa Scale of Kinesiophobia (TSK), the Knee-Self Efficacy Scale (K-SES), the Multidimensional Health Locus of Control (MHLC-C), the Knee injury and Osteoarthritis Outcome Score (KOOS) and the Anterior Cruciate Ligament- Quality of Life (ACL-QoL) questionnaires. Fifty-three patients answered the ACL-RSI twice to examine reproducibility. The ACL-RSI showed good face validity, internal consistency (Cronbach's alpha = 0.948), low floor and ceiling effects and high construct validity when evaluated against the TSK, K-SES, MHLC-C, KOOS and ACL-QoL scales. The reproducibility was also high $(I C C=0.893)$. Therefore the ACL-RSI can be used to evaluate psychological factors relevant to returning to sport after $\mathrm{ACL}$ reconstruction surgery.

Keywords: knee injury, psychological response, COSMIN 
Measurement properties ACL-RSI

\section{INTRODUCTION}

One of the most important reasons for performing anterior cruciate ligament $(A C L)$ reconstruction surgery is to allow the patient to return to sports. Orthopedic surgeons also rated the patients desire to return to sport as one of the most important factors affecting the decision of whether to operate or not (Marx et al. 2003). Despite this, many athletes do not return to their pre-injury level of sports even though they are physically rehabilitated (Feller et al. 2003; Kvist et al. 2005; Langford et al. 2008) and despite the fact that the goal of reconstruction and rehabilitation was to return to the pre-injury level (Webster et al. 2008). Most patients (85-90\%), report good knee function after $A C L$ reconstruction but less than half were able to return to their pre-injury competitive sport (Ardern et al. 2011). Studies have also shown that the reason for the low rate of return to sport may be that the patient is not prepared psychologically for a return. Fear of new injury and negative psychological response for example, has been reported to be associated with not returning to the pre-injury level of sport (Kvist et al. 2005; Tripp et al. 2007; Langford et al. 2008).

Only a small number of studies have evaluated psychological factors associated with return to sports following ACL reconstruction surgery, and no consensus exists about the best evaluation method. The Tampa Scale of Kinesiophobia (TSK) has been used and showed that fear of re-injury is a hindrance for returning to sports (Kvist et al. 2005; Tripp et al. 2007). A short form of the same questionnaire has also been used to evaluate fear of movement and re-injury at different timeframes during rehabilitation after ACL-reconstruction (Chmielewski et al. 2008) and to analyze the contribution of psychological factors to the perceived knee function (Lentz et al. 2009). The TSK was initially developed to measure pain-related fear of movement and re-injury (Kori et al. 1990). The TSK is often used with patients with chronic musculoskeletal pain and it can be questioned if the items included in the questionnaire are relevant to patients with ACLinjuries. Gobbi et al (2006) developed a psychovitality questionnaire with six questions, evaluating the patient's psychological profile related to return to sports. This included questions about the patient's expectations and motivation to return to sports. Patients who returned to sports scored higher on the psychovitality questionnaire compared to patients who did not return. However, the psychovitality questionnaire is only available in Italian, limiting its current utility (Gobbi et al. 2006). The Emotional Responses of Athletes to Injury Questionnaire (ERAIQ) measures emotional response to injury, but is not specific for emotions related to returning to sports (Morrey et al. 1999; Langford et al. 2008). Langford et al (2009) used the ERAIQ and found that although negative emotions decreased during the rehabilitation phase, there were no significant differences in the emotional responses between patients who did and did not return to their pre-injury level of sport following ACL reconstruction. Thomee et al (2006) have developed the Knee Self-Efficacy Scale (K-SES) that evaluates the perceived self-efficacy in present knee 
Measurement properties ACL-RSI

function and future physical performance. The K-SES has been shown to predict acceptable outcome and return to physical activity after ACL reconstruction (Thomee et al. 2008).

The TSK, psychovitality, ERAIQ and Knee Self-Efficacy scales examine some factors that are of importance for return to sport after ACL-injury or reconstruction. However, these scales were not developed specifically to evaluate the psychological impact of returning to sport. For that purpose, Webster et al (2008) developed the ACL-Return to Sport after Injury scale (ACL-RSI) that measures athletes' emotions, confidence in performance and risk appraisal in relation to return to sport. The ACL-RSI has been shown to discriminate between athletes who return and athletes who do not return to sport after reconstruction surgery. Furthermore, the athlete's response at 6 months post-operatively was found to be related to whether or not the athlete returned to competition by 12 months (Langford et al. 2008; Webster et al. 2008).

The primary aim of the present study was to translate the ACL-RSI from English to Swedish to enable the scale to be used in Swedish populations. The secondary aim of this study was to examine some measurement properties of the Swedish version of ACL-RSI to determine the reliability and validity of the scale in the Swedish context.

\section{MATERIALS AND METHODS}

The ACL-RSI was first translated to Swedish. The COSMIN guidelines were followed for the evaluation of the measurement properties of the ACL-RSI (Terwee et al. 2007; Mokkink et al. 2010). The original scale was also altered so that the response were given on a ten-point Likert scale ranging from 1 to 10 instead for the original $10 \mathrm{~cm}$ Visual Analogue Scale (VAS). The choice of a ten-point scale facilitated comparisons to the original $10 \mathrm{~cm}$ VAS, by only eliminating the value "0", but keeping the range $0.1-1,1.1-2$ up to 9.9-10 (10 increments).

\section{Translation procedure}

The ACL-RSI was translated and culturally adapted from English to Swedish independently by two physical therapists (ST, HL) with good knowledge of the English language. The two translations were discussed with a third physical therapist (JK). All three therapists were extensively experienced in ACL rehabilitation and two of them (ST, JK) are involved in research in the same area. One Swedish version of the questionnaire with different suggestions for wording was then reviewed by an expert group. The expert group consisted of one orthopedic surgeon and six physical therapists with varying levels of involvement in clinical work and 
Measurement properties ACL-RSI

research in rehabilitation and sports psychology. After consensus for one version, five patients ( 3 female, 2 male, mean age 23 years) with ACL-injury were interviewed and asked to answer the questionnaire and comment on the content of the questions as well as the wordings. All patients had unilateral ACL-injuries that had been reconstructed 6-12 months prior answering the questionnaires. All were active in sport prior to injury ( 4 in soccer and one in handball) and all wanted or had already returned to their sports. After revision, the questionnaire was back-translated to English by an authorized translator with English as his mother tongue. The back-translation was discussed with the inventor of the ACL-RSI, K. Webster. That translation procedure followed the recommendations by Guillemin et al (1993)(Guillemin et al. 1993). The face validity and the cross-cultural adaptation of the Swedish version were tested both in the expert group and in the testing of the five patients.

\section{Procedure for assessment of measurement properties}

The measurement properties of the ACL-RSI were evaluated using data from a package of questionnaires obtained from a consecutive group of patients who had undergone ACL-reconstruction two to five years prior to completing the questionnaires, in one of four orthopedic clinics in the region. Inclusion criteria were age 18-45 years at the time of follow up and unilateral ACL injury. Patients with associated grade 3 collateral ligament injuries, $\mathrm{PCL}$ injuries and bilateral $\mathrm{ACL}$ injuries were excluded. Medical records from 1447 patients were reviewed. Finally, 346 patients ( 219 men and 127 women, mean age 28 years, SD 8.1 years) met the inclusion criteria and were eligible for this study. Three patients declined to participate. After three reminder letters sent two weeks apart, 182 patients (response rate 53\%), 106 men and 76 women were followed up for this study. Mean age was 28.5 years (range 18-45 years, SD 8.2 years). The Tegner activity level score was a median 9 prior to injury and was reduced to median 4 at the time of follow up. Five ACL-RSI questionnaires had incomplete answers (3\% missing data). Three missed answers in one item ( $n r 8,12$ and 12 respectively), one missed answer in five items ( $n r 3,6,10,11,12$ ) and one in 9 items ( $n r$ 4-12). The mean value of the answered items was calculated.

\section{Questionnaires}

Different questionnaires were used for the validity testing of the ACL-RSI. The project specific questionnaire included questions about new injuries, and activity level before the injury and at the time of follow up (including specific questions about the reasons for not returning to same activity or same activity level for those who had not returned to their pre-injury level). There was also a specific question about risk behavior with responses on a four-point Likert scale with anchors "often take deliberate risks" to "avoid risks at any price" (Ekberg et al. 2011). Global knee function and satisfaction with activity level and knee function was measured on a ten-point scale. Symptom satisfaction (i.e. "If you, for the rest of your life, had to live with 
Measurement properties ACL-RSI

your current knee function as it was in the past week, would you feel:") was graded on a seven-point Likert scale with anchors "unhappy" to "happy" (Cherkin et al. 1996).

The Tampa Scale of Kinesiophobia (TSK) was used to measure fear of re-injury due to movement and physical activity. It comprises 17 statements (scored on a four-point Likert scale) regarding the subjective experience of the injury and physical activity. It results in one total score ranging from 17-68 where 68 indicates a high level of fear (Kori et al. 1990). A higher score on the TSK has previously been associated with not returning to sports after ACL-injury (Kvist et al. 2005). The modified Swedish version adjusted for knee injuries, was used for this study (Kvist et al. 2005).

The Knee-Self Efficacy Scale (K-SES) was developed for patients with ACL injury and used to measure the patient's perceptions of their capabilities to perform in different activities. It has 22 questions scored on an eleven-point scale. Two factors can be analyzed, perceived present self-efficacy in knee function (18 questions) and beliefs regarding future self-efficacy in knee function (4 questions). Both the total score and the sub-scores range from 0 to 10, with a higher score reflecting a higher level of self-efficacy (Thomee et al. 2006).

The Multidimensional Health Locus of Control, C-form (MHLC-C) measures different dimensions of Health Locus of Control, i.e., peoples' beliefs about whether their health is determined by their behavior or external events. The C-form is condition specific and the word "condition" was replaced with "knee problems" for the current study. The MHLC-C comprises four subsections: Internal HLC (I-HLC) (possible range 6-36), health outcomes occurring by chance (possible range 6-36), health outcomes related to the actions of doctors (possible range 3-18) and health outcomes related to the actions of other people (possible range 3-18). Higher scores indicate a higher level of contribution to the HLC from the corresponding subsection. Internal HLC is the extent to which one believes that internal factors are responsible for health/ illness. Individuals with strong internal HLC believe that a certain outcome is directly the result of their own behavior or action (Wallston et al. 1976; Lundgren et al. 2007).

The Knee injury and Osteoarthritis Outcome Score (KOOS) evaluates subjective knee function. The KOOS has five subscales evaluating symptoms, pain, function in daily life, function during sport and recreational activities and knee related quality of life. The score for each subscale ranges from 0 to 100 where 100 indicates good knee function (Roos et al. 1998).

The Anterior Cruciate Ligament- Quality of Life (ACL-QoL) measures disease-specific quality of life in patients with an $\mathrm{ACL}$ injury. The ACL-QoL questionnaire consists of 31 questions in five domains; symptoms 
Measurement properties ACL-RSI

and physical complaints, work-related concerns, recreational activities and sport participation or competition, lifestyle, and social and emotional domain (Mohtadi 1998). The modified Swedish version with 32 questions, each answered on a ten-point scale was used in the present study. The mean score of the five domains and of the entire scale is calculated with higher scores indicating a higher quality of life.

All the questionnaires used have been translated to Swedish and their measurement properties tested, with good results.

Face validity and cross cultural adaptation

The face validity and the cross-cultural adaptation of the Swedish version were tested by discussion, judgment and agreement both in the expert group and in the testing of the first 5 patients.

Internal consistency

In order to confirm the uni-dimensionality of the scale, a principal component analysis was performed. The Cronbach's alpha statistic was calculated to examine the inter-item correlations in the scale. Cronbach's alpha between 0.70 and 0.95 is considered a strong correlation (Terwee et al. 2007).

Floor or ceiling effects

Floor or ceiling effects refer to content validity, and their presence indicates that extreme items are missing in the scales. The percentages of responders who scored the lowest (i.e. scored 1) or highest (i.e. scored 10) in each separate question on the ACL-RSI were documented. In addition, the percentage that scored below 2 or above 9 in the overall ACL-RSI score was also documented. Floor or ceiling effects for an entire questionnaire are considered to be present if more than $15 \%$ of respondents score the lowest or highest possible score (Terwee et al. 2007).

\section{Criterion validity}

The ACL-RSI is a new scale developed to measure the psychological impact of returning to sport following $\mathrm{ACL}$ reconstruction. No other questionnaires or "gold standards" exist that measure the same properties, therefore the criterion validity of the Swedish version of the ACL-RSI was not assessed.

\section{Construct validity}

Construct validity was evaluated by testing nine predefined hypotheses that were developed by the authors. The hypotheses, ordered in level of importance, were:

1. Patients who had returned to sports activities would score higher on the ACL-RSI than patients who had not returned to sports activities 
Measurement properties ACL-RSI

2. Patients who had returned to their previous activity level would score higher on the ACL-RSI than patients who had not returned to their previous activity level

3. Patients who were satisfied with their activity level, with their global knee function and had a high symptom satisfaction would score higher on the ACL-RSI.

4. Patients who scored high on the KOOS, would score high on the ACL-RSI. The Quality of Life subscale would be highly correlated with the ACL-RSI

5. Patients who scored high on the ACL-QoL, would score high on the ACL-RSI. Higher correlations would be found for the subscales "participation", "lifestyle" and "social and emotional"

6. Patients who scored low on the TSK, would score high on the ACL-RSI

7. Patients who scored high on the K-SES, would score high on the ACL-RSI

8. Patients who scored high on the IHLC-C, would score high on the ACL-RSI

9. Patients who scored high on the risk behavior question, would score high on the ACL-RSI

\section{Reproducibility}

For reliability testing, the 62 patients who first answered the first questionnaire ( 37 men and 25 women, mean age 29 years, SD 9.3 years), received the ACL-RSI twice in order to evaluate reproducibility. Some questions about new injuries and stability of knee function since their latest answer were also included. The inclusion criteria for the reliability testing were; response to the second questionnaire between 14 and 80 days after the first was completed and stable knee condition as determined by the question of new injury. The time period between test-retest was chosen to minimize the risk for remembering the answer from the first questionnaire. For our patients who were two to five years post ACL-reconstruction, it is unlikely that the psychological response to returning to sports would change during 80 days if no new injury had occurred.

Fifty-three out of the 62 patients returned the questionnaires, three reported that they had sustained a new injury since they had answered the questionnaire the first time and two had more than 80 days between test and re-test. The results of 48 patients ( 25 men and 23 women, mean age 29 years, SD 9.5 years) who completed the ACL-RSI twice within 80 days (mean 40 days, SD 16 days, range 15-80 days) were included in the analysis. Two questionnaires at the re-test had missing data in one question each ( $\mathrm{nr} 9$ and 8 respectively) ( $2 \%$ missing data). The mean value of the answered items was calculated.

To examine the test-retest reliability, i.e. the degree to which patients can be distinguished from each other (Terwee et al. 2007), two-way random intra-class correlation coefficients for absolute agreement (ICC 2,1$)$ were calculated. An ICC of $>0.70$ is considered the minimum standard for reliability testing. The 
Measurement properties ACL-RSI

measurement error, i.e. exactly how close the scores for the repeated measurements were, was represented by the standard error of the measurement $\left(S E M=S_{1} \times v(1-r)\right.$, where $\mathrm{SD}_{1}$ is the standard deviation at baseline and $r$ is the reliability coefficient from the ICC). The smallest detectable change (SDC) for the individual score, i.e. the within-person change in score $\left(\mathrm{SDC}_{\text {ind }}=1.96 \times \sqrt{ } 2 \times \mathrm{SEM}\right)$ and SDC for the group score $\mathrm{SDC}_{\text {group }}\left(\mathrm{SDC}_{\text {group }}=\mathrm{SDC}_{\text {ind }} / \mathrm{Vn}\right)$ was calculated according to Beaton et al (2000) and Terwee et al (2007) (Beaton 2000; Terwee et al. 2007). The SDC is the lowest change that can confidently (95\% confidence) be considered for the individual score $\left(\mathrm{SDC}_{\text {ind }}\right)$ or the group score $\left(\mathrm{SDC}_{\text {group }}\right)$ as exceeding measurement error.

\section{RESULTS}

Face validity and cross cultural adaptation

The expert committee and the five patients who were interviewed concluded that the constructs included in the ACL-RSI were relevant for the patient population and the purpose of the questionnaire. The questions were easy to understand and no specific cultural adaptations were needed during the translation procedure.

\section{Internal consistency}

The principal component analysis confirmed the presence of a single underlying factor with an eigenvalue of 7.7. This factor explained $64.1 \%$ of the total variance within the sample. The Cronbach's alpha statistic was 0.948 , which indicates a strong correlation between the 12 items.

\section{Floor or ceiling effects}

The overall mean score for ACL-RSI was 5.03 (SD 2.18, range 1-10). The floor and ceiling effects of each question and the overall score were acceptable. Between 8 and $20 \%$ of the answers for each question were 1 (floor effect) and between 2 and 20\% of the answers for each question were 10 (ceiling effect). For the overall score, $6.7 \%$ of participants scored below 2 and $4.5 \%$ of participants scored above 9.

\section{Construct validity}

All nine hypotheses regarding the relationships between scores on the ACL-RSI and scores on other impairment-specific questionnaires were confirmed (Tables 1 and 2). Patients who had returned to sports activities, scored higher on the ACL-RSI when compared to patients who had not returned to sports activities, and patients who had returned to their previous activity level scored higher on the ACL-RSI when compared to patients who had not returned to their previous activity level or had not returned to sports at 
Measurement properties ACL-RSI

all. Patients who scored high on the ACL-RSI also scored high at the global knee function scale, were satisfied with their activity level and knee function, and had a high symptom satisfaction. In addition, patients who scored high on the KOOS, ACL-QoL, K-SES and IHLC scales also scored high on the ACL-RSI. Patients who scored low on the TSK scored high on the ACL-RSI, and patients who scored high on the risk behaviour question also scored high on the ACL-RSI. All correlation co-efficients for the comparisons described, including the comparison between the ACL-RSI and subscales of the KOOS and ACL-QoL are displayed in Table 2. The relationship between the ACL-RSI and the ACL-QoL participation subscale score accounted for $73 \%$ of the variance between scores, and the relationship between the ACL-RSI and the total ACL-QoL score explained $66 \%$ of the variance. The moderately strong correlations between the ACL-RSI and global knee function, KOOS QoL subscale, ACL-QoL lifestyle and social/emotional subscales and the K-SES demonstrated each relationship had at least $50 \%$ common variance (Table 2 ).

\section{Reproducibility}

The mean score for the ACL-RSI was $5.1(S D=2.1)$ at the first occasion and $5.2(S D=2.3)$ at the second occasion ( $n=48)$. The paired t-test showed no significant difference between the occasions $(p=0.355)$. The $\mathrm{ICC}_{2,1}$ was 0.893 , SEM was 0.7 and $\mathrm{SDC}_{\text {ind }}$ was 1.9 and $\mathrm{SDC}_{\text {group }}$ was 0.3 .

\section{DISCUSSION}

The Swedish version of the ACL-RSI was shown to be an internally consistent, valid and reliable questionnaire for patients after $\mathrm{ACL}$ reconstruction. In accordance with the English version (Webster et al. 2008), the factor analysis revealed that the questionnaire primarily evaluates one dimension. Therefore, the three psychological responses that are included in the ACL-RSI i.e. emotions, confidence in performance and risk appraisal cannot be separated and one total score is calculated. In addition, the high inter-item correlations (internal consistency) indicated the constructs are not far separated from each other. Tripp et al have previously shown that negative emotions, fear of re-injury and athletic confidence in the ability to return to sports are associated with each other, strengthening the fact that it may be difficult to separate these responses (Tripp et al. 2007).

Fear of re-injury has previously been shown to be a hindrance for return to sports (Kvist et al. 2005). Tripp et al found that fear of re-injury was the unique predictor for return to sports when compared to negative emotions and catastrophizing (Tripp et al. 2007). Fear of re-injury was assessed with the TSK in both these studies. The TSK has not been tested for responsiveness in patients with ACL-injuries or after ACLreconstruction. Some of the items in this questionnaire may not be relevant for the patients after ACL- 
reconstruction. The ACL-RSI has two items about fear of new injury, i.e. items number 4 and 5 . The first of these items ( $\mathrm{nr} 4$ ), has been adapted from the ACL-QoL questionnaire (Mohtadi 1998). Other emotions that are evaluated in the ACL-RSI are nervousness, frustration and stress (total three items). These emotions have been shown to be affected after sports injury and during rehabilitation after injury (Wiese-Bjornstal et al. 1998; Brewer et al. 2007).

Athletic confidence is an important component of optimal performance. Tripp et al (2007) showed that negative emotions are associated with athletic confidence in the ability to return to sports. Tripp et al (2007) used the Sports Self-Confidence Inventory to evaluate athletic confidence. That questionnaire consists of 13 general items regarding an individual's confidence in various aspects of participation in sports (Tripp et al. 2007). In the ACL-RSI, two (nr 1 and 11) of the five items about confidence are general related generally to sports confidence and three items ( $\mathrm{nr} 4,5$ and 8) are specific to confidence in performance related to the knee function. After an $\mathrm{ACL}$ reconstruction, the athlete may have lowered confidence due to suboptimal knee function. In accordance, Heijne et al (2008) found in an interview study that the participants experienced reduced confidence specifically related to knee-joint stability (Heijne et al. 2008). Thus, it may be of importance to use the ACL-RSI that evaluates both aspects of confidence, i.e. general sports confidence and specific confidence in performance related to knee function, in order to identify adequate treatment strategies for the individual patient.

Two items about the cognitive risk appraisal are included in the ACL-RSI. This area has not previously been investigated in relation to return to sports. Risk taking behavior has previously been shown to be associated with an increased injury risk (Junge 2000; Ekberg et al. 2011). In the current study, the ACL-RSI was significantly correlated (although weakly) to the risk behavior question. This would appear to suggest preliminary evidence of the construct validity of the ACL-RSI scale, although further research is needed to fully elucidate the influence of risk appraisal on return to sport outcomes.

Some of the measurement properties of the ACL-RSI have been evaluated previously for the English version. In accordance with the English version, we found that the mean score for the ACL-RSI was near the middle of the scale scoring (5.6) and ranged from 1 to 10. In addition, the floor and ceiling effects of the total score were less than $15 \%$ indicating a good distribution of the answers. The absence of floor and ceiling effects indicates that the ACL-RSI can be used as an outcome after interventions without risking missing an intervention effect because of people occupying minimum or maximum scores. Again in accordance with the original English version, we found that patients who had returned to sport scored significantly higher at the ACL-RSI when compared to patients who had not returned to sport (Webster et al. 2008). 
It should be noted that the use of a 1-10 scale in the current study was a modification from the original report which used a $10 \mathrm{~cm}$ visual analogue scale (VAS) (Webster et al. 2008). An eleven point check-box scale has also been used (Langford et al. 2008). A check-box scale response format is less time consuming to score and anecdotally patients seem to find this format easier to complete than a VAS. This study, along with the previous reports (Langford et al. 2008) shows that both scale formats appear to be valid. More importantly, irrespective of which response format has been used clear differences have been reported between patients who have and haven't returned to sport.

We also tested the construct validity of the scale by testing predefined hypotheses, and by correlating the results with patients' self-reported knee function (KOOS), disease specific quality of life (ACL-QoL), fear of re-injury (TSK), knee self efficacy (K-SES) and internal health locus of control (I-HLC). It was expected that patients with better subjective knee function would be more likely to perceive themselves as psychologically prepared to return to sport, particularly at their pre-injury level. All hypotheses that were tested demonstrated significant correlations between the ACL-RSI and other outcome measures that have been widely evaluated in patients following ACL injury. The fact that all correlations were significant appears to suggest that the ACL-RSI does evaluate aspects of the psychological response thought to be important in determining return to sport outcomes. Strong correlations $(r=>0.8)$ were found between the ACL-RSI and the ACL-QoL participation subscale and ACL-QoL total score. Moderately strong correlations ( $r$ $=>0.7$ ) were found between the ACL-RSI and global knee function, KOOS-QoL subscale, ACL-QoL lifestyle and social/emotional subscales and the K-SES scale. The relationships between these variables and the ACLRSI demonstrated at least $50 \%$ common variance between outcomes. In spite of the fact that there are similarities in some of the questions included in ACL-QoL, KOOS-QoL subscale and ACL-RSI, these relationships may suggest that aspects of quality of life, subjective knee function, and social and emotional factors are relevant to athletes' perceptions of their psychological preparedness to return to their preinjury sports participation level, and the maintenance of participation at the pre-injury level in the medium term following surgery. Additionally, the correlation of the ACL-RSI to scales evaluating cognitive risk appraisal, emotions and athletic confidence provides further evidence of the construct validity of the ACLRSI in this patient population.

The reproducibility of the ACL-RSI has not been tested previously. We found that the reproducibility was high, with low measurement error. When investigating the clinical effect of an intervention on one individual, the smallest detectable change exceeding the measurement error is 1.9 on the ten-point ACL-RSI scale. When comparing two groups, the minimal detectable change is 0.3 indicating that changes in group mean score above 0.3 points can be detected with $95 \%$ confidence. 
One limitation of our study was the relatively long time between completing the first and second questionnaires for the test re-test evaluation (mean 40 days). The COSMIN recommendation is that the time interval should be long enough to prevent recall bias and short enough to ensure that patient characteristics have not changed regarding the construct to be measured. A time interval of around two weeks is often purported to be appropriate. Our goal was to have approximately three weeks between the answers. This was not always possible due to practical reasons. However, the patients were all two to five years post-operative, and it can be reasonably expected that their psychological status related to return to sports would be relatively stable at that time following surgery if no new injury had occurred. In addition, the two patients who reported a new injury during that time were excluded from the analysis. A second limitation of this study is the response rate of $53 \%$, and it is possible that patients that completed the survey did so because they were satisfied with their knee function. Therefore, it is possible that the results overestimated the return to sport outcomes and psychological response. However, the response rate of the current study is similar to other previously published cross-sectional survey studies (Asch et al. 1997) and higher than the $50 \%$ minimum purported to minimize the effects of bias (Dillman 1978; Rea et al. 1997). Two other explanations for the low response rate are also possible. Many patients comment that they prefer to answer internet-based questionnaires. In addition, all the patients who are having an ACLreconstruction in Sweden are asked to fill questionnaires for the ACL-registry at one, two and five years post-operatively, resulting in a possible tiredness of answering questionnaires. In the present study, the subjects were asked to answer to 129 questions.

\section{PERSPECTIVES}

One can argue that there is no need for new questionnaires in the area of $A C L$ injuries. Though, many studies have shown that all the patients do not return to their previous activity level or sport in spite of good knee function. This may suggest other factors such as psychological response may influence return to sport outcomes, and thus, demonstrate the importance of examining such factors. Clearly, reliable, valid and responsive instruments are required in order to enable accurate examination of psychological factors relevant to returning to sport following $A C L$ injury and surgery. The ACL-RSI may assist in the identification of patients who have the functional ability to return to sport but have a psychological hindrance to do so. Further research should aim to answer the question of whether it is possible to help these patients with different interventions to gain sports confidence and minimize negative emotions related to sports participation. Another reason for development of a new questionnaire is to be able to identify factors that affect returning to sports. Low scores at the ACL-RSI may be an indicator that the muscle function or the surgical procedure is not the only factor that hinders return to sport following ACL reconstruction surgery. 


\section{ACKNOWLEDGEMENTS}

The authors would like to thank Helena Lundgren, Physiotherapist, for valuable help during the translation procedure and Caroline Terwee, PhD, Dep of Epidemiology and Biostatistics and the EMGO Inst of Health and Care Research, Amsterdam, Netherlands for valuable advice in analysis and reporting of data according to the COSMIN guidelines. This study was funded by the Swedish National Centre for Research in Sports (CIF), the R\&D-centre Sörmland and Linkoping University. 


\section{REFERENCES}

Ardern, C. L., K. E. Webster, N. F. Taylor and J. A. Feller. Return to sport following anterior cruciate ligament reconstruction surgery: a systematic review and meta-analysis of the state of play. Br J Sports Med 2011: 45(7): 596-606.

Asch, D. A., M. K. Jedrziewski and N. A. Christakis. Response rates to mail surveys published in medical journals. J Clin Epidemiol 1997: 50(10): 1129-1136.

Beaton, D. E. Understanding the relevance of measured change through studies of responsiveness. Spine (Phila Pa 1976) 2000: 25(24): 3192-3199.

Brewer, B. W., A. E. Cornelius, J. H. Sklar, J. L. Van Raalte, H. Tennen, S. Armeli, J. R. Corsetti and J. C. Brickner. Pain and negative mood during rehabilitation after anterior cruciate ligament reconstruction: a daily process analysis. Scand J Med Sci Sports 2007: 17(5): 520-529.

Cherkin, D. C., R. A. Deyo, J. H. Street and W. Barlow. Predicting poor outcomes for back pain seen in primary care using patients' own criteria. Spine (Phila Pa 1976) 1996: 21(24): 2900-2907.

Chmielewski, T. L., D. Jones, T. Day, S. M. Tillman, T. A. Lentz and S. Z. George. The association of pain and fear of movement/reinjury with function during anterior cruciate ligament reconstruction rehabilitation. J Orthop Sports Phys Ther 2008: 38(12): 746-753.

Dillman, D., A. Mail and Telephone Surveys: The Total Design Method.(1978) New York, NY, Wiley.

Ekberg, J., T. Timpka, H. Ramel and L. Valter. Injury rates and risk-factors associated with eventing: a total cohort study of injury events among adult Swedish eventing athletes. Int J Inj Contr Saf Promot 2011: 1-7.

Feller, J. A. and K. E. Webster. A randomized comparison of patellar tendon and hamstring tendon anterior cruciate ligament reconstruction. Am J Sports Med 2003: 31(4): 564-573.

Gobbi, A. and R. Francisco. Factors affecting return to sports after anterior cruciate ligament reconstruction with patellar tendon and hamstring graft: a prospective clinical investigation. Knee Surg Sports Traumatol Arthrosc 2006: 14(10): 1021-1028.

Guillemin, F., C. Bombardier and D. Beaton. Cross-cultural adaptation of health-related quality of life measures: literature review and proposed guidelines. J Clin Epidemiol 1993: 46(12): 1417-1432.

Heijne, A., K. Axelsson, S. Werner and G. Biguet. Rehabilitation and recovery after anterior cruciate ligament reconstruction: patients' experiences. Scand J Med Sci Sports 2008: 18(3): 325-335.

Junge, A. The influence of psychological factors on sports injuries. Review of the literature. Am J Sports Med 2000: 28(5 Suppl): S10-15.

Kori, S. H., R. P. Miller and D. D. Todd. Kinisophobia: A new wiew of chronic pain behavior. Pain Management 1990: (Januari/Februari): 35-43. 
Measurement properties ACL-RSI

Kvist, J., A. Ek, K. Sporrstedt and L. Good. Fear of re-injury: a hindrance for returning to sports after anterior cruciate ligament reconstruction. Knee Surg Sports Traumatol Arthrosc 2005: 13(5): 393-397.

Langford, J., K. E. Webster and J. A. Feller. A prospective longitudinal study to assess psychological changes following anterior cruciate ligament reconstruction surgery. Br J Sports Med 2008.

Lentz, T. A., S. M. Tillman, P. A. Indelicato, M. W. Moser, S. Z. George and T. Chmielewski. Factors associated with function after anterior cruciate ligament reconstruction. Sports Health 2009: 1(1): 47-53.

Lundgren, S., E. Eurenius, Å. Olausson and H. Opava. The Swedish version of the Multidimensional Health Locus of Control scales, form C. Aspects of reliability and validity in patients with rheumatoid arthritis. Adv Physiotherapy 2007: 9: 16-22.

Marx, R. G., E. C. Jones, M. Angel, T. L. Wickiewicz and R. F. Warren. Beliefs and attitudes of members of the American Academy of Orthopaedic Surgeons regarding the treatment of anterior cruciate ligament injury. Arthroscopy 2003: 19(7): 762-770.

Mohtadi, N. Development and validation of the quality of life outcome measure (questionnaire) for chronic anterior cruciate ligament deficiency. Am J Sports Med 1998: 26(3): 350-359.

Mokkink, L. B., C. B. Terwee, D. L. Patrick, J. Alonso, P. W. Stratford, D. L. Knol, L. M. Bouter and H. C. de Vet. The COSMIN checklist for assessing the methodological quality of studies on measurement properties of health status measurement instruments: an international Delphi study. Qual Life Res 2010: 19(4): 539-549.

Morrey, M. A., M. J. Stuart, A. M. Smith and D. M. Wiese-Bjornstal. A longitudinal examination of athletes' emotional and cognitive responses to anterior cruciate ligament injury. Clin J Sport Med 1999: 9(2): 63-69.

Rea, L. M. and R. A. Parker. Designing and Conducting Survey Research: A Comprehensive Guide.(1997) San Francisco, CA, Jossey-Bass.

Roos, E. M., H. P. Roos, L. S. Lohmander, C. Ekdahl and B. D. Beynnon. Knee Injury and Osteoarthritis Outcome Score (KOOS)--development of a self-administered outcome measure. Journal of Orthopaedic \& Sports Physical Therapy 1998: 28(2): 88-96.

Terwee, C. B., S. D. Bot, M. R. de Boer, D. A. van der Windt, D. L. Knol, J. Dekker, L. M. Bouter and H. C. de Vet. Quality criteria were proposed for measurement properties of health status questionnaires. J Clin Epidemiol 2007: 60(1): 34-42.

Thomee, P., P. Wahrborg, M. Borjesson, R. Thomee, B. I. Eriksson and J. Karlsson. A new instrument for measuring self-efficacy in patients with an anterior cruciate ligament injury. Scand J Med Sci Sports 2006: 16(3): 181-187. 
Measurement properties ACL-RSI

Thomee, P., P. Wahrborg, M. Borjesson, R. Thomee, B. I. Eriksson and J. Karlsson. Self-efficacy of knee function as a pre-operative predictor of outcome 1 year after anterior cruciate ligament reconstruction. Knee Surg Sports Traumatol Arthrosc 2008: 16(2): 118-127.

Tripp, D. A., W. Stanish, A. Ebel-Lam, B. W. Brewer and J. Birchard. Fear of reinjury, negative affect and catastrophizing predicting return to sport in recreational athletes with anterior cruciate ligament injuries at 1 year postsurgery. Rehabil Psychol 2007: (52): 74-81.

Wallston, B. S., K. A. Wallston, G. D. Kaplan and S. A. Maides. Development and validation of the health locus of control (HLC) scale. J Consult Clin Psychol 1976: 44(4): 580-585.

Webster, K. E., J. A. Feller and C. Lambros. Development and preliminary validation of a scale to measure the psychological impact of returning to sport following anterior cruciate ligament reconstruction surgery. Phys Ther Sport 2008: 9(1): 9-15.

Wiese-Bjornstal, D. M., A. M. Smith, S. M. Shaffer and M. A. Morrey. An integrated model of response to sport injury: psychological and socialogical dynamics. J Appl Sport Psychol 1998. 
Measurement properties ACL-RSI

Tables

Table 1

ACL-RSI scores in patients who returned or not to same activity or activity level.

$\begin{array}{llllll} & \text { YES } & \text { NO } & \begin{array}{l}\text { Mean } \\ \text { difference }\end{array} & \begin{array}{l}95 \% \mathrm{Cl} \text { of } \\ \text { difference }\end{array} & \mathrm{p} \\ \text { Returned to } & 6.1 \text { (SD 1.9) } & \begin{array}{l}4.2(\text { SD 2) } \\ \text { same activity }\end{array} & 1.9 & 1.3-2.5 & <0.001 \\ & \mathrm{n}=73 & \mathrm{n}=101 & & & \\ \text { Returned to } & 7.0(1.8) & 4.3(\text { SD 1.8) } & 2.76 & 2.1-3.4 & <0.001 \\ \text { same activity } & \mathrm{n}=48 & \mathrm{n}=124 & & & \\ \text { level } & & & & & \end{array}$


Measurement properties ACL-RSI

\section{Table 2}

Correlation between ACL-RSI scores and other outcome measures

$\begin{array}{lrrr} & r & r^{2} & p \\ \text { Global knee function } & 0.713 & 0.51 & <0.001 \\ \text { Satisfaction with activity level } & 0.486 & 0.24 & <0.001 \\ \text { Symptom satisfaction } & -0.561 & 0.31 & <0.001 \\ \text { KOOS - symptoms } & 0.479 & 0.23 & <0.001 \\ \text { KOOS - pain } & 0.510 & 0.26 & <0.001 \\ \text { KOOS - ADL } & 0.484 & 0.23 & <0.001 \\ \text { KOOS - sport } & 0.594 & 0.35 & <0.001 \\ \text { KOOS - QoL } & 0.718 & 0.51 & <0.001 \\ \text { ACL-QoL total } & 0.815 & 0.66 & <0.001 \\ \text { ACL-QoL symptom } & 0.607 & 0.37 & <0.001 \\ \text { ACL-QoL work } & 0.462 & 0.21 & <0.001 \\ \text { ACL-QoL participation } & 0.852 & 0.73 & <0.001 \\ \text { ACL-QoL lifestyle } & 0.753 & 0.57 & <0.001 \\ \text { ACL-QoL social and emotional } & 0.726 & 0.53 & <0.001 \\ \text { TSK } & -0.689 & 0.47 & <0.001 \\ \text { K-SES } & 0.705 & 0.50 & <0.001 \\ \text { IHLC-C } & 0.287 & 0.08 & <0.001 \\ \text { Risk behavior } & 0.321 & 0.10 & <0.001\end{array}$


Appendix: ACL-RSI - Swedish version

Átergång till idrott efter främre korsbandsskada ACL-RSI SCALE ACL-Return to Sport after Injury Scale

Instruktioner: Vänligen svara på följande frågor med tanke på den huvudsakliga idrottsaktivitet du utövade innan skadan. Besvara varje fråga genom att markera med ett kryss i den ruta som beskriver, hur du upplever situationen just nu i relation till de två ytterligheterna.

Namn:

Datum:

1. Är du säker på att du kan utöva din idrottsaktivitet på samma nivå som tidigare?

\begin{tabular}{l}
$\begin{array}{l}\text { Inte alls } \\
\text { sāker }\end{array}$ \\
\cline { 2 - 7 }
\end{tabular}

2. Tror du det är sannolikt att du skadar ditt knä igen genom att delta i din idrottsaktivitet?

\begin{tabular}{l}
$\begin{array}{c}\text { Extremt } \\
\text { sannolikt }\end{array}$ \\
\cline { 2 - 3 }
\end{tabular}

3. Är du orolig för att utöva din idrottsaktivitet?

\begin{tabular}{c|l|l|l|l|l|l|l|l|l|l|}
$\begin{array}{c}\text { Extremt } \\
\text { orolig }\end{array}$ & 1 & 2 & 3 & 4 & 5 & 6 & 7 & 8 & 9 & 10 \\
\hline
\end{tabular}

4. Är du säker på att ditt knä inte kommer att ge vika vid utövandet av din idrottsaktivitet?

Inte alls
sāker $\quad$\begin{tabular}{l|l|l|l|l|l|l|l|l|l|}
1 & 2 & 3 & 4 & 5 & 6 & 7 & 8 & 9 & 10 \\
\hline
\end{tabular}

5. Är du säker på att du kan utöva din idrottsaktivitet utan att bekymra dig för ditt knä?

Inte alls
sāker $\quad$\begin{tabular}{l|l|l|l|l|l|l|l|l|l|}
1 & 2 & 3 & 4 & 5 & 6 & 7 & 8 & 9 & 10 \\
\hline
\end{tabular}


6. Upplever du att det är frustrerande att behöva ta hänsyn till ditt knä med avseende på din idrottsaktivitet?

Extremt

frustrerande

\begin{tabular}{|l|l|l|l|l|l|l|l|l|l|}
\hline 1 & 2 & 3 & 4 & 5 & 6 & 7 & 8 & 9 & 10 \\
\hline
\end{tabular}

Inte alls

frustrerande

7. Är du rädd för att skada ditt knä igen vid utövandet av din idrottsaktivitet?

\begin{tabular}{c|c|c|c|c|c|c|c|c|c|c|}
$\begin{array}{c}\text { Extremt } \\
\text { rädd }\end{array}$ & 1 & 2 & 3 & 4 & 5 & 6 & 7 & 8 & 9 & 10 \\
$\begin{array}{c}\text { Inte alls } \\
\text { rädd }\end{array}$
\end{tabular}

8. Är du säker på att ditt knä klarar att bibehålla kontroll under belastning? Inte alls sāker

\begin{tabular}{|l|l|l|l|l|l|l|l|l|l|}
\hline 1 & 2 & 3 & 4 & 5 & 6 & 7 & 8 & 9 & 10 \\
Helt säker
\end{tabular}

9. Är du rädd att du, av en olyckshändelse, skadar ditt knä vid utövandet av din idrottsaktivitet?

\begin{tabular}{l|l|l|l|l|l|l|l|l|l|l|}
$\begin{array}{c}\text { Extremt } \\
\text { rädd }\end{array}$ & 1 & 2 & 3 & 4 & 5 & 6 & 7 & 8 & 9 & 10 \\
$\begin{array}{c}\text { Inte alls } \\
\text { rädd }\end{array}$
\end{tabular}

10. Har tankar på att vara tvungen att genomgå operation och rehabilitering igen, hindrat dig från att utöva din idrottsaktivitet?

Alltid

\begin{tabular}{|l|l|l|l|l|l|l|l|l|l|}
\hline 1 & 2 & 3 & 4 & 5 & 6 & 7 & 8 & 9 & 10 \\
\hline
\end{tabular}

11. Är du säker på din förmåga att kunna prestera bra i din idrottsaktivitet?

Inte alls
sāker $\quad$\begin{tabular}{l|l|l|l|l|l|l|l|l|l|}
1 & 2 & 3 & 4 & 5 & 6 & 7 & 8 & 9 & 10 \\
\hline
\end{tabular}

12. Känner du dig avspänd inför att utöva din idrottsaktivitet?

Inte alls

avspänd

\begin{tabular}{|l|l|l|l|l|l|l|l|l|l|}
\hline 1 & 2 & 3 & 4 & 5 & 6 & 7 & 8 & 9 & 10 \\
\hline
\end{tabular}

Helt

avspänd 